\title{
Histone deacetylase inhibition induces odor preference memory extension and maintains enhanced AMPA receptor expression in the rat pup model
}

\author{
Sriya Bhattacharya, ${ }^{1}$ Bandhan Mukherjee, ${ }^{1}$ Jules J.E. Doré, ${ }^{1}$ Qi Yuan, ${ }^{1}$ Carolyn W. Harley, ${ }^{2}$ \\ and John H. McLean ${ }^{1}$ \\ ${ }^{1}$ Division of BioMedical Sciences, Memorial University of Newfoundland, St. John's, Newfoundland, Canada A1B3V6; ${ }^{2}$ Department of \\ Psychology, Memorial University of Newfoundland, St. John's, Newfoundland, Canada A1B3X9
}

\begin{abstract}
Histone deacetylase (HDAC) plays a role in synaptic plasticity and long-term memory formation. We hypothesized that trichostatin-A (TSA), an HDAC inhibitor, would promote long-term odor preference memory and maintain enhanced GluAl receptor levels that have been hypothesized to support memory. We used an early odor preference learning model in neonate rat pups that normally produces only 24-h memory to test behavior and examine receptor protein expression. Our behavioral studies showed that intrabulbar infusion of TSA, prior to pairing of the conditioned stimulus (peppermint odor) with the unconditioned stimulus (tactile stimulation), prolonged 24-h odor preference memory for at least $9 \mathrm{~d}$. The prolonged odor preference memory was selective for the paired odor and was also observed using a specific HDAC6 inhibitor, tubacin, supporting a role for histone acetylation in associative memory. Immunoblot analysis showed that GluAl receptor membrane expression in the olfactory bulbs of the TSA-treated group was significantly increased at $48 \mathrm{~h}$ unlike control rats without TSA. Immunohistochemistry revealed significant increase of GluAl expression in olfactory bulb glomeruli $5 \mathrm{~d}$ after training. These results extend previous evidence for a close relationship between enhanced GluAl receptor membrane expression and memory expression. Together, these findings provide a new single-trial appetitive model for understanding the support and maintenance of memories of varying duration.
\end{abstract}

During early life, rat pups need to recognize their mother's odor for survival. The association of the pup with their mother is critical as odor recognition is used to maintain proximity to their dam. In the 24-h odor preference learning model, on post-natal day (PND 6) rat pups learn to prefer a novel odor when it is paired for $10 \mathrm{~min}$ with an intermittent tactile stimulation (stroking) that mimics maternal care. This learning model normally induces a $24 \mathrm{~h}$ memory, but not longer (Sullivan and Leon 1986; Sullivan et al. 1986; McLean et al. 2005). The memory is determined by time spent over the conditioned odor compared with normal bedding. To induce longer or extended memories (i.e., $48 \mathrm{~h}$ or longer) multiple spaced training sessions are normally required (Fontaine et al. 2013).

To investigate the intracellular correlates of shorter and longer duration long-term memories it would be ideal to modulate a single-trial memory pharmacologically so that comparisons of protein transcription and translation could be made following both a training that results in $24 \mathrm{~h}$ memory and the same training when it leads to multiday memory. Previously, we have shown that manipulations of cAMP cascade activation itself during single-trial odor preference training can extend memory duration. For example, pairing a novel odor with intrabulbar infusion of the PKA agonist (Sp-cAMP) as the unconditioned stimulus (US) enhances memory by extending normal 24 -h retention to $48-72 \mathrm{~h}$ (Grimes et al. 2012). In other experiments from our laboratory a normally ineffective dose of isoproterenol $(1 \mathrm{mg} / \mathrm{kg})$ in combina-

\section{Corresponding author: mclean@mun.ca}

Article is online at http://www.learnmem.org/cgi/doi/10.1101//m.045799. 117. tion with the phosphodiesterase IV (PDE4) inhibitor, cilomilast, extended memory to $4 \mathrm{~d}$ (McLean et al. 2005). Cilomilast prevents cyclic-AMP breakdown extending CREB phosphorylation. However, the normally effective dose of isoproterenol $(2 \mathrm{mg} / \mathrm{kg})$ along with PDE4 was unable to induce prolonged memory. It was hypothesized that a weaker dose of the $\beta$-AR agonist $(1 \mathrm{mg} /$ $\mathrm{kg}$ isoproterenol) in combination with cilomilast helps to maintain a better balance of kinase/phosphatase signaling (McLean et al. 2005).

In recent years, several epigenetic regulation studies have also suggested that long-term memory can have multiple durations, all of which involve gene translation and transcription (Guan et al. 2002). Epigenetic mechanisms such as chemical modifications of DNA and histones (acetylation and deacetylation) appear to play vital roles in memory formation and maintenance over longer time frames (Levenson and Sweatt 2005; Zovkic et al. 2013). It is now accepted that histone acetylation, achieved by inhibiting deacetylation, via histone deacetylase (HDAC) inhibitors, is a major molecular mechanism in the regulation of transcription underlying memory extension (Fischer et al. 2007; Haettig et al. 2011). A role for HDAC inhibition in extending long-term memory was first demonstrated in contextual fear conditioning using the HDAC inhibitor trichostatin-A (TSA) (Levenson et al. 2004). In 2007, Vecsey et al. (2007) showed that TSA modulates CREB binding protein

2017 Bhattacharya et al. This article is distributed exclusively by Cold Spring Harbor Laboratory Press for the first 12 months after the full-issue publication date (see http://learnmem.cshlp.org/site/misc/terms.xhtml). After 12 months, it is available under a Creative Commons License (AttributionNonCommercial 4.0 International), as described at http://creativecommons. org/licenses/by-nc/4.0/. 
(CBP)-CREB interactions and that histone acetylation is required for contextual fear memory consolidation. Their work suggested that CBP-CREB interactions and histone acetylation provide regulatory mechanisms for enhancing memory and synaptic plasticity (Korzus et al. 2004; Vecsey et al. 2007). Recent findings also show that intrabulbar TSA infusion facilitates the duration of aversive olfactory learning in young rats (Wang et al. 2013). However, all of these TSA studies are related to aversive learning. Surprisingly, there is no HDAC inhibition-mediated prolonged single-trial preference memory model reported in the literature.

The purpose of the present study is to assess whether a normally 24-h appetitive memory model can be extended beyond $24 \mathrm{~h}$ by intrabulbar HDAC inhibition using TSA or the specific HDAC6 inhibitor tubacin to examine potential mechanisms involved in such memory extension. Here we extend olfactory preference memory using HDAC inhibition and support previous findings of both a correlation and a causal relationship between memory expression and GluA1 receptor enhancement at sites related to memory relevant synaptic plasticity in the olfactory bulb (Cui et al. 2011).

\section{Results}

\section{HDAC inhibition does not strengthen odor preference initially}

We know that one 10-min session of pairing a conditioning odor with an unconditioned stimulus on postnatal day 6 (PND 6) by pairing for $10 \mathrm{~min}$ a conditioned odor with an unconditioned tactile stimulus leads to $24 \mathrm{~h}$ but not 48 -h memory (McLean et al. 2005). In the first experiment, we wished to determine whether an HDAC inhibitor could strengthen the 24-h preference for the conditioned odor more than that produced by the tactile stimulation alone. Pups give odor only at training served as the nonlearning control while odor plus stroking $(\mathrm{O} / \mathrm{S})$ served as the normal learning control. We found that the addition of the HDAC inhibitor TSA did not make the preference for the conditioned peppermint odor $(\mathrm{O} / \mathrm{S}$ group) any stronger at 24 -h memory (Fig. 1). There was a statistically significant difference between groups as determined by one-way ANOVA $\left[F_{(2,12)}=54.99, P=0.000000009\right]$. A Tukey's post hoc test revealed that both the odor + stroking $(P<0.001)$ and the TSA + odor + stroking $(P<0.001)$ groups were significantly different from the odor only control group. However, there was no significant difference between the odor + stroking group and the TSA + odor + stroking group $(P=0.700)$ indicating that the TSA treatment did not provide an initial strengthening of the preference for the conditioned odor that could account for the extended memory observed in subsequent experiments (see Fig. 2).

\section{HDAC inhibition induces odor preference memory extension}

To identify the role of HDAC inhibition in prolonging long-term memory (i.e., eliciting $>1$-d memory), odor preference memory testing was performed on rat pups at different intervals following training; 2, 4, 5, and $9 \mathrm{~d}$. Pups were tested only once and we additionally asked if HDAC inhibition could prolong memory in the absence of an unconditioned stimulus (stroking) at the time of training. Therefore, the nonlearning control (odor only: $\mathrm{O} / \mathrm{O}$ ) was compared with drug only (TSA) and drug plus unconditioned stimulus conditions (TSA $+\mathrm{O} / \mathrm{S}$ ). Our behavioral data revealed robust memory in the odor + stroking TSA-treated groups compared with the control groups. One-way ANOVA with a Tukey's post hoc test was performed to analyze the behavioral data. Animals that received bilateral intrabulbar infusion of TSA immediately before odor + stroke $(\mathrm{O} / \mathrm{S})$ training on PND 6 showed significantly

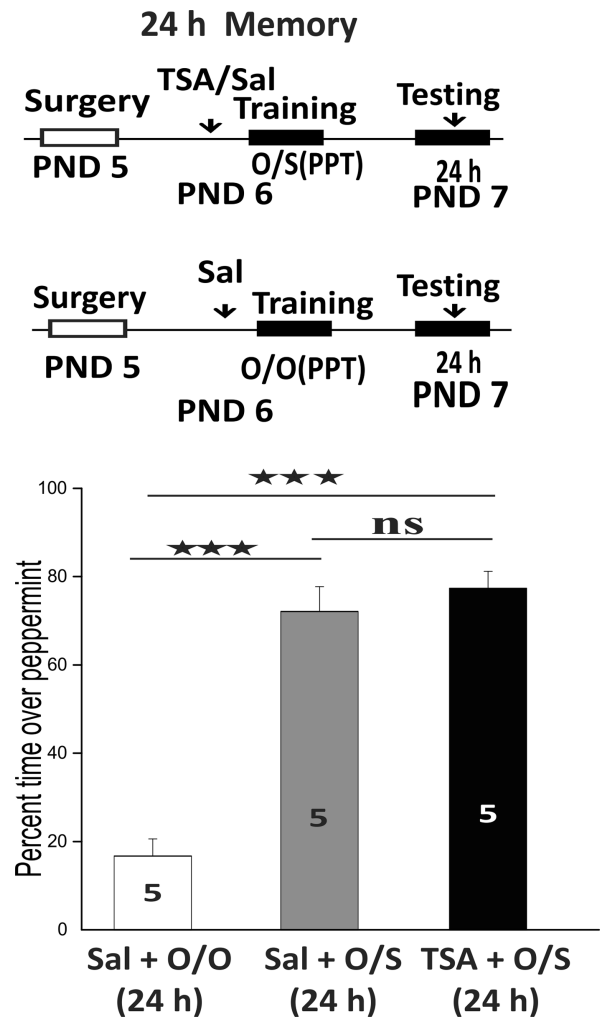

Figure 1. HDAC inhibition using TSA does not potentiate the preference for the conditioned odor (peppermint: PPT) $24 \mathrm{~h}$ after odor preference training (TSA + O/S PPT) when compared with pups given tactile stimulation paired with odor (O/S PPT) at training. $N$ values are provided in each bar.

greater preference for peppermint odor on PND 8 (2 d) compared with the control group (Fig. $2 \mathrm{~A}, F_{(2,8)}=102.42 ;{ }^{* * *} P<0.001$ ). Remarkably, the preference memory was observed (Fig. 2 ) in the TSA-treated group up to $9 \mathrm{~d}$ after the single 10-min training session on PND 6 (4 d: $F_{(2,10)}=67.699 ;{ }^{* * *} P<0.001 ; 5$ d: $F_{(2,13)}=169.31$; ${ }^{* * *} P<0.001 ; 9$ d: $\left.F_{(2,9)}=20.5478 ;{ }^{* *} P<0.001\right)$.

\section{An HDAC 6 inhibitor extends memory and is specific to the conditioned odor}

To identify whether another HDAC inhibitor could extend memory and to determine whether HDAC inhibition enhances memory specifically to the conditioned odor (rather than a generalized enhanced memory to odors) we designed an experiment using tubacin, a specific HDAC 6 inhibitor (Cuadrado-Tejedor et al. 2017; Perry et al. 2017) and a different odor in addition to peppermint. Our prolonged memory model revealed that there was no preference memory in TSA + O/O group $5 \mathrm{~d}$ after training (Fig. 2). However, in that experiment, we did not examine the possibility that pups given 10-min odor plus stroking training on PND6 might be able to remember the conditioned odor beyond $24 \mathrm{~h}$, although we, and others, have never seen that previously. Therefore, the tubacin experiment included an odor + stroking group in addition to the nonlearning control $(\mathrm{O} / \mathrm{O})$ and HDAC6 inhibitor experimental group. Tubacin-infused rat pups were trained in the presence of peppermint odor + stroking for $10 \mathrm{~min}$ and tested in the presence of either peppermint (Fig. 3A) or orange (Fig. 3B) odor $5 \mathrm{~d}$ after training. A one-way ANOVA showed a significant difference between groups when pups were trained and tested with 
A
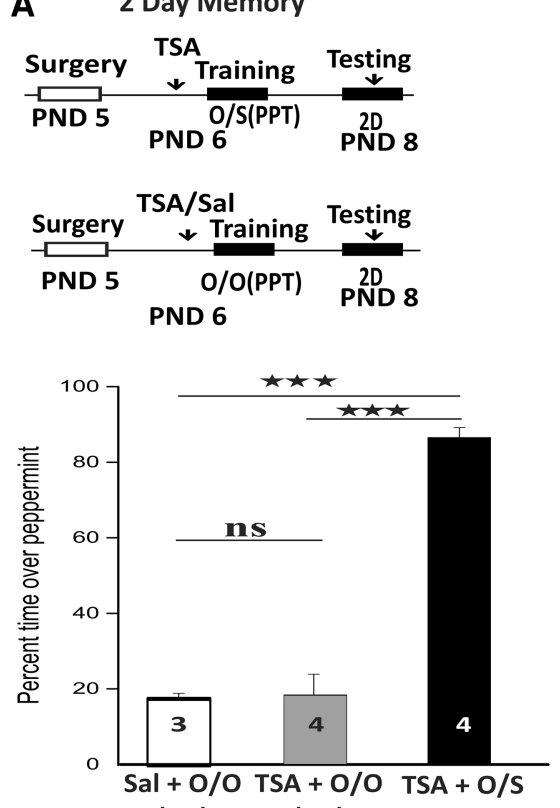

(2D)

(2D)

(2D)
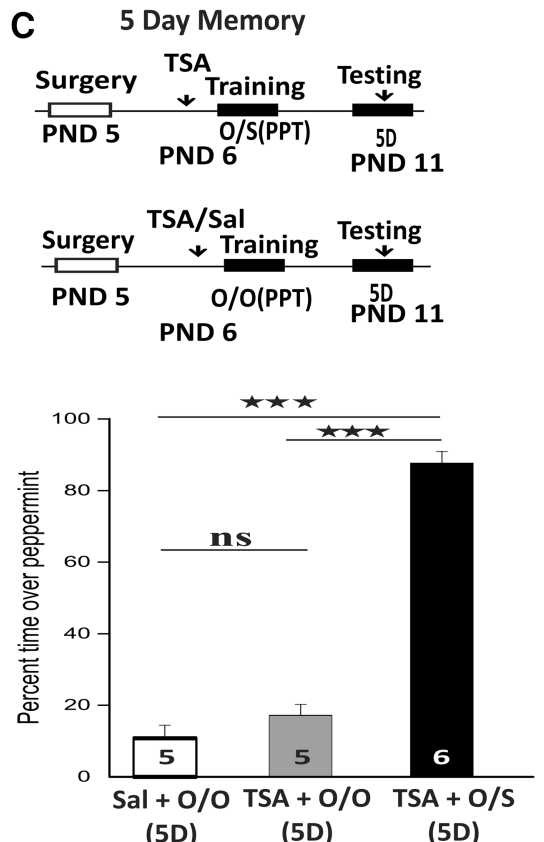

(5D)
(5D)
B
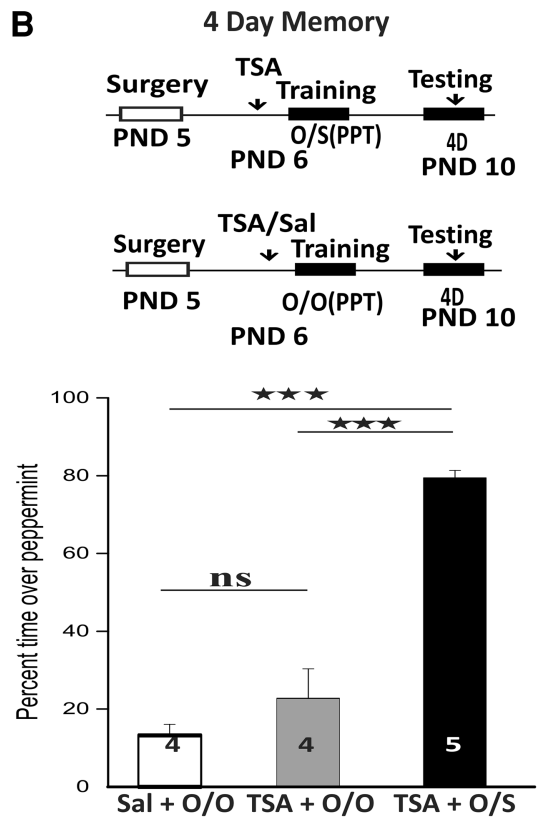

(4D)

D
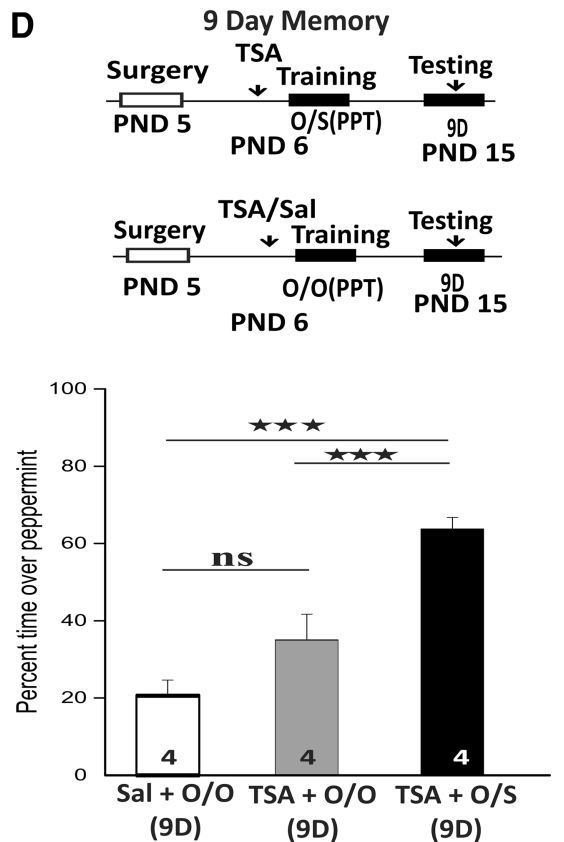

Figure 2. HDAC inhibition induces odor preference memory extension. $(A=D)$ Time course analysis of preference behavioral studies reveals significant memory in TSA-treated $\mathrm{O} / \mathrm{S}$ trained groups as contrasted with groups given odor only $(\mathrm{O} / \mathrm{O})$ or odor only plus TSA at 2, 4, 5, or $9 \mathrm{~d}$ after odor preference training.

peppermint odor $\left[F_{(2,15)}=20.22, P=0.000055\right]$ and a post hoc Tukey's test revealed the tubacin treatment led to a significant difference in odor preference compared with the $\mathrm{O} / \mathrm{S}$ trained group not given tubacin $(P<0.001)$ and the odor only $(\mathrm{O} / \mathrm{O})$ control group $(P<0.001)$ while the $\mathrm{O} / \mathrm{S}$ group was not significantly different from the nonlearning $(\mathrm{O} / \mathrm{O})$ control group (Fig. 3A). Thus, this experiment confirmed, using a specific HDAC inhibitor instead of a pan HDAC inhibitor such as TSA, that HDAC inhibition extends memory when compared with pups given 10 min of odor + stroking on PND 6. In pups that were trained with peppermint but test-
(4D)

(4D)

ed with orange (Fig. 3B), one-way ANOVA showed no differences between the three training groups $\left[F_{(2,12)}=0.102, P=0.903\right]$. Thus, tubacin does not induce a generalized odor preference to normally aversive odors. We previously showed pups have the ability to show preference to the normally aversive orange odor if they are trained in the presence of orange odor (Grimes et al. 2015). This, and the present findings, suggests tubacin-enhanced odor preference memory is specific to the paired odor.

GluAl expression is increased at $48 \mathrm{~h}$ after training in the TSA-treated odor preference memory model The effect of TSA-induced prolonged odor preference memory on AMPA receptor expression was explored to determine whether memory length could be correlated with enhanced GluA1 expression in the olfactory bulb. Immunoblots were performed at three different time points ( $24 \mathrm{~h}, 48 \mathrm{~h}$, and $5 \mathrm{~d}$ ). GluA1 expression was analyzed by two-way ANOVA followed by Tukey's post hoc comparisons with both time and groups as factors $\left(F_{(1,28)}=21.44\right)$. Animals received either saline paired with an odor only (baseline, nonlearning control, Sal $+\mathrm{O} / \mathrm{O})$, saline with odor + stroke (24-h learning condition, $\mathrm{Sal}+\mathrm{O} / \mathrm{S}$ ) or TSA paired with odor + stroke (prolonged memory condition, $\mathrm{TSA}+\mathrm{O} / \mathrm{S})$. According to our initial behavioral data (Fig. 1), neither of the nonlearning control groups $(\mathrm{Sal}+\mathrm{O} / \mathrm{O}$ and TSA $+\mathrm{O}$ / O) showed preference memory when the control treatment was paired with peppermint odor. Therefore, for the immunoblot experiment (Fig. 4), we used the nonlearning control group $(\mathrm{Sal}+\mathrm{O} / \mathrm{O})$ to normalize the experimental data at different time points. At $24 \mathrm{~h}$ following training, the expression of the GluA1 subunit (shown as relative optical density) from synaptic and extra-synaptic membrane fractions from whole olfactory bulbs in the TSA + $\mathrm{O} / \mathrm{S}$ and $\mathrm{Sal}+\mathrm{O} / \mathrm{S}$ groups did not differ significantly (Fig. $4 \mathrm{~A}, P>0.05$ ). At $48 \mathrm{~h}$ following training, increased GluA1 expression was observed in the TSA $+\mathrm{O} / \mathrm{S}$ group (Fig. $\left.4 \mathrm{~B},{ }^{* *} P<0.0001\right)$ compared with the $\mathrm{Sal}+\mathrm{O} / \mathrm{S}$ group. However, at $5 \mathrm{~d}$ following training GluA1 expression in $\mathrm{TSA}+\mathrm{O} / \mathrm{S}$ group, while higher, was not significantly different from the $\mathrm{Sal}+\mathrm{O} / \mathrm{S}$ group (Fig. $4 \mathrm{C}, P>0.05$ ) .

Immunohistochemical expression of GluAl in the glomerular layer of olfactory bulbs $5 \mathrm{~d}$ after training

The inability to detect a significant difference between "normal" and extended memory groups using immunoblots $5 \mathrm{~d}$ after training suggested the possibility that whole-bulb analysis might have diluted the signal of increased GluA1 expression. Therefore, we 
A
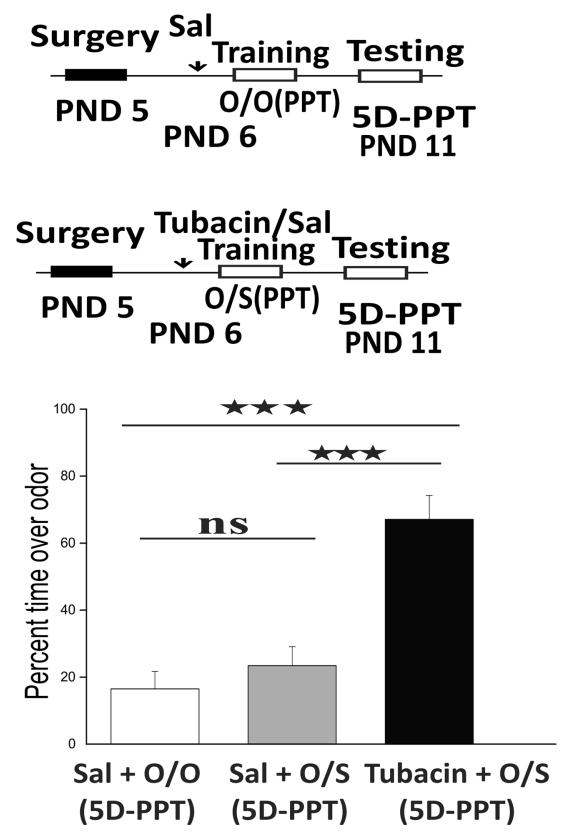

B
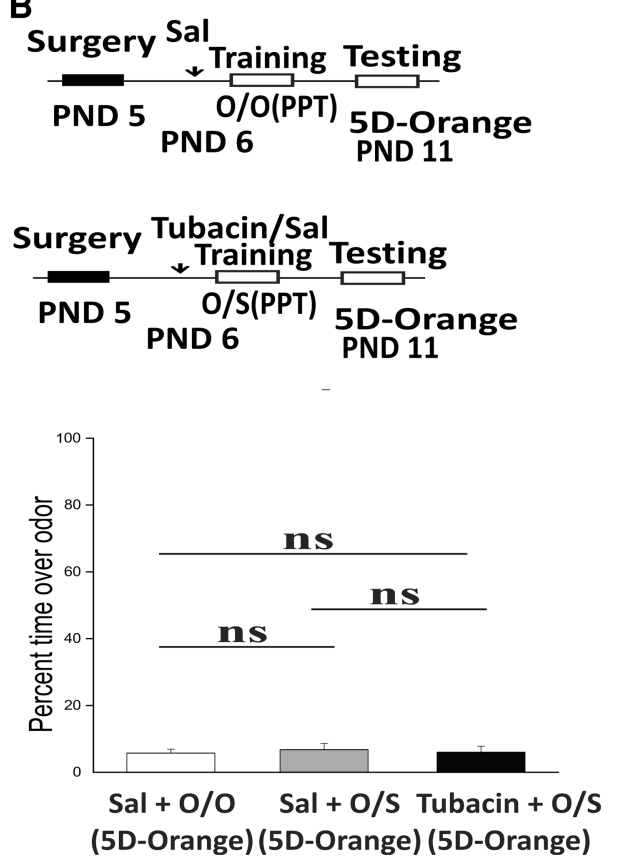

Figure 3. (A) The HDAC 6 inhibitor tubacin infused into the olfactory bulbs induced extended (5 d) odor preference memory compared with the nonlearning control (odor only at training) or the normal 24-h memory group (sal $+\mathrm{O} / \mathrm{S}$ ). $n=6$ for each group. (B) When pups were trained with peppermint (PPT) in the presence of tubacin but tested with orange odor, the pups did not show preference for the orange odor suggesting specificity to the trained odor. $n=5$ for each group. The experimental protocol is above the graph. Error bars indicate mean \pm SEM.

A
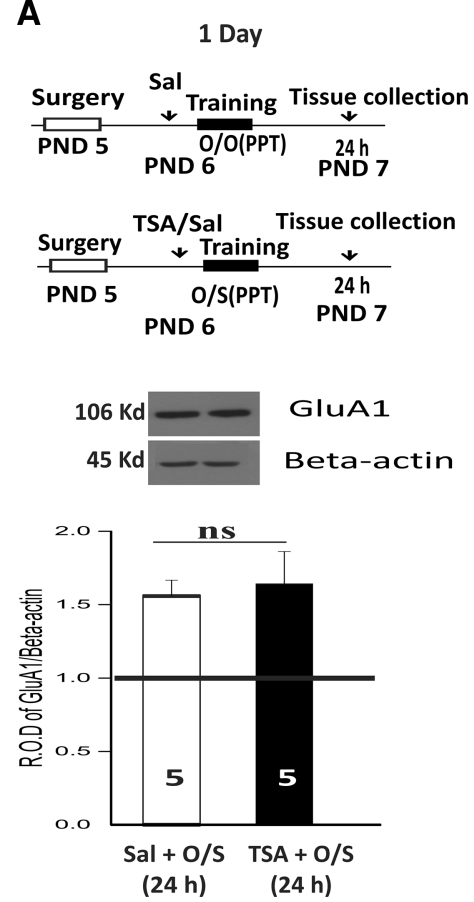

B
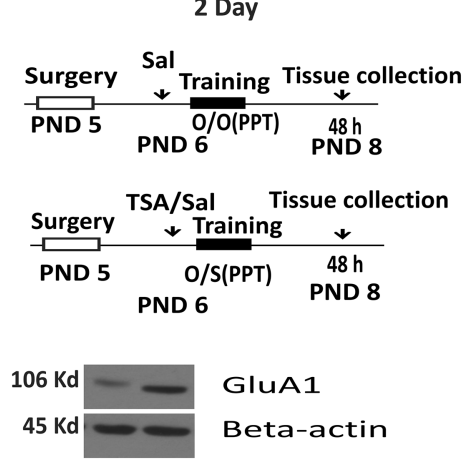

GIuA1

Beta-actin
C

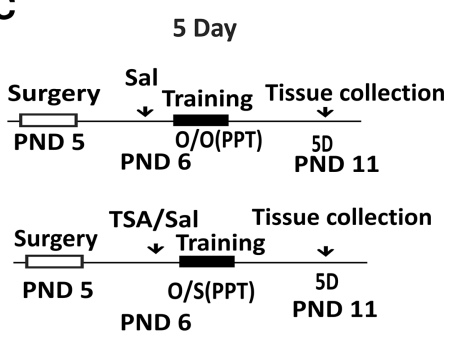

$106 \mathrm{Kd}=$ GIuA1

$45 \mathrm{Kd}=$ Beta-actin decided if we focused on learning-related quadrants and layers (instead of whole bulb) we might be able to better assess learning-induced changes in the receptor. To explore this issue, GluA1 expression was examined $5 \mathrm{~d}$ after training using immunohistochemical (IHC), which enabled protein analysis in specific layers of the olfactory bulb. In this study, an intra-animal control was used whereby TSA was infused into one $\mathrm{OB}$ and saline into the contralateral $\mathrm{OB}$ after which the pup was trained with $\mathrm{O} / \mathrm{S}$ pairing (Fig. 5). Paired two-tail $t$-tests revealed significantly increased GluA1 label within the dorsolateral and dorsomedial quadrants of the glomerular layer (dorsolateral: $t_{(7)}=2.962 ;{ }^{*} P<0.05$; dorsomedial: $\left.t_{(10)}=2.85 ;{ }^{*} P<0.05\right)$ in the TSA-infused side compared with vehicle-infused side (Fig. 6B,C). In contrast, there was no significant difference of GluA1 expression observed in the external plexiform cell layer (EPL) of the dorsolateral and dorsomedial quadrants (dorsolateral: $P>0.05$; dorsomedial: $P>0.05)$ in the TSA-treated versus vehicle-treated side (Fig. 6D,E). This is consistent with a strengthening of input to peppermint odor encoding glomeruli through increased AMPA receptor insertion that is observable $5 \mathrm{~d}$
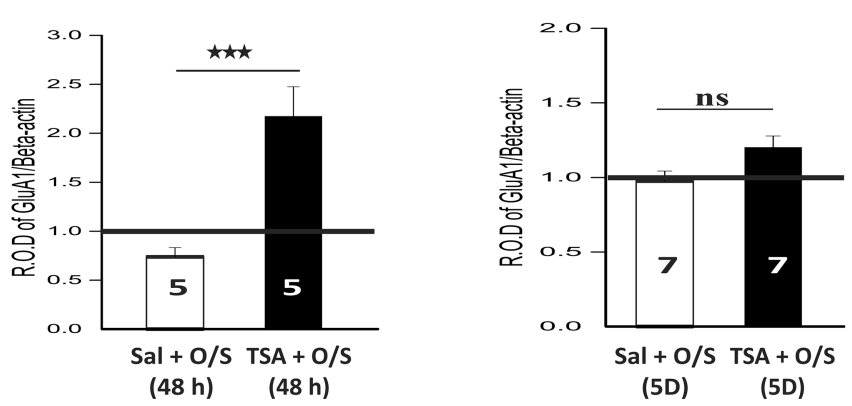

Figure 4. Immunoblots of GluA1 expression showing the relative optical density of GluA1/ $\beta$-actin (mean \pm SEM) in the neonatal rat pups at $24 \mathrm{~h}, 48 \mathrm{~h}$, and $5 \mathrm{~d}$ post-training. All data are normalized to Sal + Odor control groups (represented as a horizontal line). Representative bands and experimental protocol are above each graph. (A) Time course analysis of GluA1/ $\beta$-actin in rat pups shows no significant difference in the TSA-treated group compared with the $\mathrm{Sal}+\mathrm{O} / \mathrm{S}$ group $24 \mathrm{~h}$ after training. (B) Forty-eight hours post-training reveals a significantly higher GluA1 expression in TSA-treated groups relative to the $\mathrm{Sal}+\mathrm{O} / \mathrm{S}$ group. (C) GluA1 expression in the TSA + O/S group did not show any significant difference compared with the Sal + O/S group $5 \mathrm{~d}$ following training. 
A

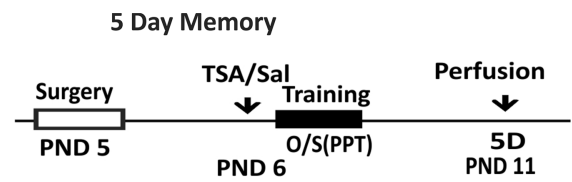

B

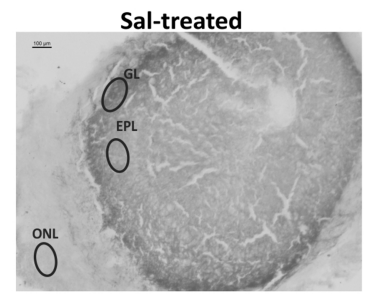

Left OB

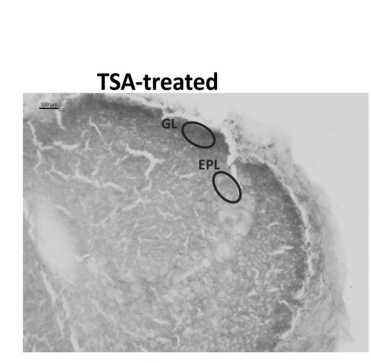

Right OB

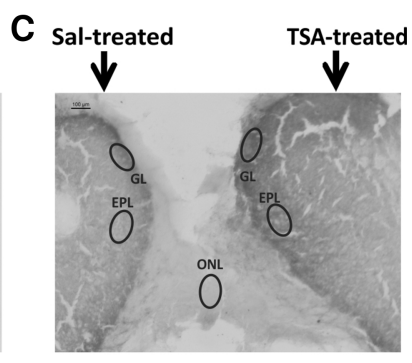

Left OB
Right OB

Figure 5. Immunohistochemical (IHC) expression of GluA1 in the glomerular and external plexiform layer of the olfactory bulbs $5 \mathrm{~d}$ after training. Representative IHC localization of GluA1 (TSA-treated right $O B$ versus Vehicle-treated left $O B$ ) in different quadrants of the $O B$. (A) Experimental protocols is at the top. (B) Left and right OB dorsolateral quadrant of the glomerular layer $(\mathrm{GL})$ and external plexiform layer (EPL). (C) Dorsomedial quadrant of GL and EPL of the olfactory bulb in intra-animal-infused PND 11 pups sacrificed $5 \mathrm{~d}$ after odor preference training. $(B)$ and $(C)$ are at the same magnification as the bar in $B(100 \mu \mathrm{m})$.

after training. We also examined pups given odor only at training and treated in one olfactory bulb with TSA. Intra-animal comparisons of those olfactory bulbs revealed no significant differences between treatment groups indicating TSA treatment by itself did not influence GluA1 expression (data not shown).

\section{Discussion}

\section{Summary of major findings}

In our experiments, we established a model in which early odor preference memory was extended for at least $9 \mathrm{~d}$ after one trial training on PND 6 consisting of 10 min odor + stroking training combined with intrabulbar infusion of TSA prior to training. Wang et al. (2013) had previously reported that odor + intrabulbar TSA at the same dose on PND11 produced odor aversion even without footshock. This suggested that intrabulbar TSA in older pups readily induced aversion. At PND6, while there was no evidence of odor preference induction seen when TSA alone was paired with odor, TSA strongly enhanced the preference effects of the stroking unconditioned stimulus, while one might have expected the opposite given Wang's findings. This may be an age-related effect as PND 6 pups do not readily learn odor aversions. Nonetheless, the epigenetic effect of antagonizing histone deacetylation is, in this context, even more compelling as an enhancement of memory strength/duration.

Our results with the specific HDAC6 inhibitor tubacin are particularly interesting as HDAC6 is thought to primarily deacetylate lysine on tubulin and other cytosolic proteins (Perry et al. 2017). Does this suggest that the acetylation promoted by tubacin and TSA are related to cytosolic protein effects rather than DNA histone acetylation effects? While this is a possibility, we speculate that the nuclear effects of HDAC6 are equally likely to contribute to the extended memory seen here. In a microarray study of rat pup odor preference learning we found that the expression of genes related to cell adhesion are up-regulated (M Nartey unpubl.). Recent evidence suggests the nuclear targets of HDAC6 inhibition enhance cell adhesion (Mobley et al. 2017) and this is a plausible mechanism for memory extension. An off-target effect of HDAC6 inhibition via tubacin is promotion of sphingolipid production

(Siow and Wattenberg 2014), which was also related to learning in our microarray study of rat pup odor preference learning. The cytosolic effects of HDAC6 inhibition increase mitochondrial transport (Chen et al. 2010), another feature of network circuit changes supporting memory consolidation or expression. Finally, HDAC6 inhibition in conjunction with phosphodiesterase inhibition promotes LTP and rescues spine density changes and cognitive dysfunction in mice modeling Alzheimer's disease (Cuadrado-Tejedor et al. 2017). The specific effect(s) of HDAC6 and histone deacetylation inhibition contributing to memory extension in the present experiments remain to be identified.

We also examined the relation between GluA1 membrane localization and memory extension. Western blot experiments suggested that the expression of GluA1 in the crude membrane fraction that contains synaptoneurosomes was increased at $48 \mathrm{~h}$ after training and this increased GluA1 expression was also observed immunohistochemically in the glomerular layer $5 \mathrm{~d}$ after conditioning when memory expression also occurred. Our Western blot data also revealed that there was no significant difference in GluA1 expression at $24 \mathrm{~h}$ after training between the two learning groups, the TSA $+\mathrm{O} / \mathrm{S}$ group compared with the $\mathrm{Sal}+\mathrm{O} /$ $S$ group, but the drug-treated group showed significantly greater expression at $48 \mathrm{~h}$ when only that group showed memory. These results are consistent with earlier evidence that 24-h odor preference memory requires increased expression of AMPA receptors for memory expression where GluA1expression was significantly increased at $24 \mathrm{~h}$ but not $48 \mathrm{~h}$ in pups given odor preference conditioning (Cui et al. 2011). Both the TSA and the control group showed the same levels. This also suggests TSA did not produce a stronger GluR1 enhancement at $24 \mathrm{~h}$. However, at $48 \mathrm{~h}$, when preference memory is not normally expressed in single-trial animals and IHC-demonstrated Glu1 receptors return to control levels (Cui et al. 2011), the TSA group's increased GluA1 expression is consistent with memory extension. Thus, we speculate that the mechanism for prolonged memory is not an initial "super" enhanced expression of GluA1, but more likely an enhanced continual expression of the receptor. We also found that prolonged memory was specific to the paired odor consistent with a selective role of TSA in enhancing normal memory pathways. A pairing control was not used in the TSA aversive pup learning model (Wang et al. 2013) and may be important to examine since aversive odor learning established using intrabulbar disinhibition as the unconditioned stimulus produces nonpairing specific odor aversion (Okutani et al. 1999).

\section{Relation between long-lasting memory and GluAl expression}

Several studies suggest that increased glutamatergic AMPA receptors are the substrate for long-term plasticity and long-term memory expression (Lynch and Baudry 1984; Lu et al. 2001; Malinow and Malenka 2002). More specifically, increases in the AMPA receptor GluA1 subunit is a prime candidate for the expression of LTP (Selcher et al. 2012). Membrane-associated AMPA receptor subunit GluA1 was shown to be increased in the amygdala $24 \mathrm{~h}$ after fear conditioning (Yeh et al. 2006). In 2011, Cui et al. (2011) 
A

\begin{tabular}{lcc} 
& $\begin{array}{c}5 \text { Day Memory } \\
\text { TSA/Sal }\end{array}$ & Perfusion \\
Surgery & $\downarrow$ & $\boldsymbol{\downarrow}$ \\
\hline PND 5 & PND 6/S(PPT) & 5D \\
& & PND 11
\end{tabular}

B

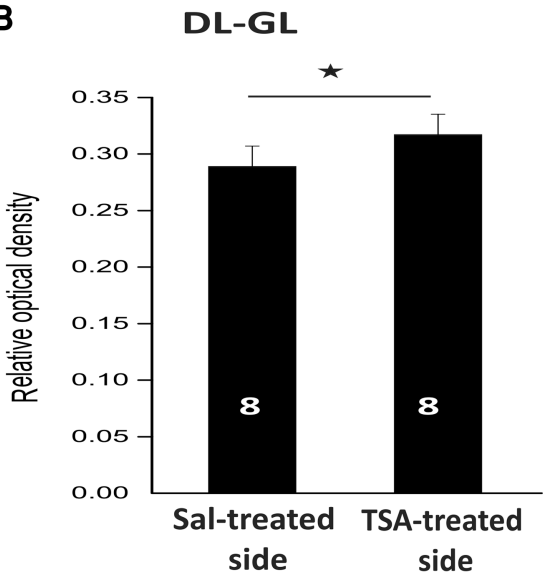

D

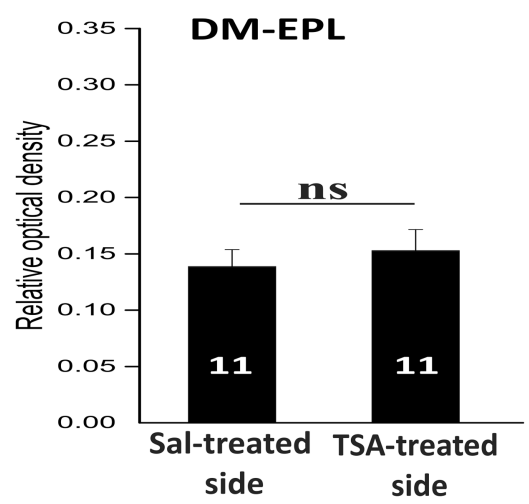

C

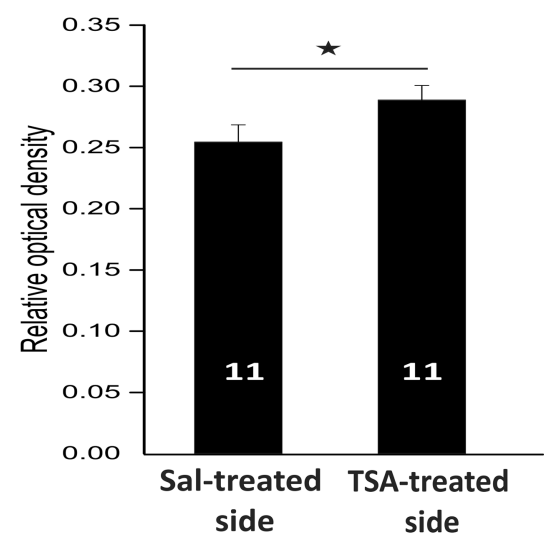

E

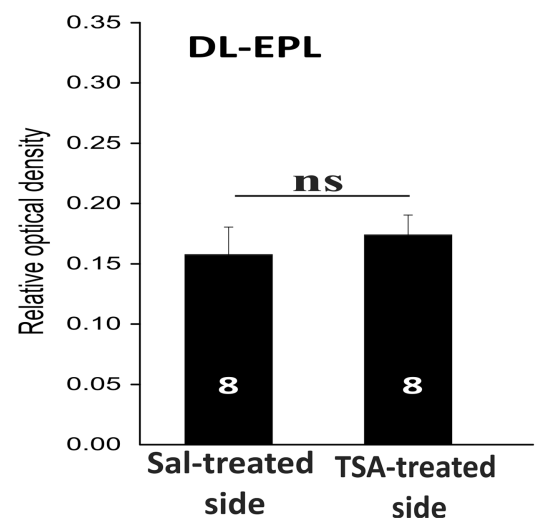

Figure 6. (A) Experimental protocol is above the graph. Graphs showing the density of GluA1 expression in various regions including: $(B)$ dorsolateral quadrant of the glomerular layer (DL-GL), $(C)$ dorsomedial quadrant of the glomerular layer (DM-GL). (D) Dorsomedial quadrant of the external plexiform layer (DM-EPL), and $(E)$ dorsolateral quadrant of the external plexiform layer (DL-EPL) of the OB. Quantitative analysis revealed significantly higher expression of GluA1 in the DL-GL and DM-GL layers of TSA-treated right OB relative to vehicle-treated left OB. However, no significant difference is observed in comparisons of animal treatments in the DM-EPL and DL-EPL layer.

showed that membrane GluA1 levels were increased in the OB glomerular layer $24 \mathrm{~h}$ after conditioning in the appetitive odor preference learning model, but this increase was no longer observed $48 \mathrm{~h}$ after training. In addition, odor preference behavior or memory was not expressed $48 \mathrm{~h}$ after conditioning. These results suggest that changes in GluA1 expression correlate with memory expression. Further, in the Cui et al. studies, blockade of GluA1 increases prevented odor preference memory induction arguing for a causal role for GluA1 increases in mediating odor preference learning.

Present results using the TSA-induced prolonged odor preference memory model show that GluA1 increases $48 \mathrm{~h}$ after training using immunoblot techniques and remains elevated in the glomerular layer of the OB (using IHC) at least $5 \mathrm{~d}$ after odor preference training. In this study, the immunoblot technique was unable to show a significant difference of GluA1 expression $5 \mathrm{~d}$ after training, while IHC did. This is likely due to the differences in sensitivity of the two methods, in addition to the fact that samples used for immunoblots used both the synaptic + extra synaptic membrane fractions of the whole $\mathrm{OB}$, thus limiting the signal-to-noise ratio. Alternatively, immunoblot data at $48 \mathrm{~h}$ suggest there may be a stronger GluA1 expression change at that earlier time which may become recalibrated and focused at longer time points consistent with hypotheses of membrane receptor homeostasis. Therefore, it is not surprising that increased GuA1 expression was not seen using immunoblotting from the membranous fractions of whole $\mathrm{OB}$ at $5 \mathrm{~d}$ posttraining. Consistent with this hypothesis, the IHC experiment found increased GluA1 expression was localized to the dorsolateral and the dorsomedial quadrant of the glomerular layer $5 \mathrm{~d}$ after training, when odor preference memory is also expressed behaviorally. This is consistent with a role for increased excitatory strength in these glomeruli in mediating odor preference behavior.

The glomerular layer of the $\mathrm{OB}$, which receives odor input, is likely to have a crucial role in the plasticity changes that underlie peppermint preference learning (Yuan et al. 2002). The dorsolateral quadrant (DL) of the glomerular layer, responsive to several compounds including carvone, is a key component of peppermint extract (Diaz-Maroto et al. 2008), acetophenone, and eugenol, while the dorsomedial quadrant (DM) responses are activated by components which include organic acids (Bozza and Kauer 1998; Kikuta et al. 2013). Accordingly, these two quadrants of the glomerular layer (DL and DM) are likely to be critical for peppermint odor preference learning changes. In summary, current results are consistent with the AMPA receptor hypothesis of long-lasting memory and provide a strong correlation between GluA1 expression in the appropriate glomerular layer quadrants and memory extension. These findings do not address the potential for other receptors and factors to be involved in the sustained memory. Such possibilities would require further investigation.

\section{Conclusions}

This study provides the first example of a single trial, appetitive odor preference extended memory model following HDAC inhibition. Consistent with previous studies, we also demonstrate that this prolonged memory is related to GluA1 membrane expression. IHC data suggest that GluA1 expression occurs selectively in the dorsolateral and dorsomedial quadrants of the glomeruli, but not in the associated external plexiform layer. This extended memory is specific to the paired odor. To date, there is no other model that shows $9 \mathrm{~d}$ extended odor preference memory following a single 10-min training trial. Thus, these studies are the first to show the effectiveness of the pan HDAC inhibitor TSA and the specific HDAC6 inhibitor in producing such a prolongation of memory, 
and particularly of appetitive memory. This unique model will help to illuminate the mechanisms for long-lasting preference memory in the future. Future work will be needed to reveal the molecular mechanisms of HDAC inhibition-mediated single-trial odor preference memory extension.

\section{Materials and Methods}

\section{Animals}

Sprague Dawley (Charles River, Saint-Constant, Quebec, Canada) rat pups of both sexes were used in this study. The day of birth was considered PND 0. Litters were culled to 12 rat pups on PND 1. Not more than one animal of each sex, per litter, was assigned to each training condition. Animals were housed in temperaturecontrolled rooms $\left(20^{\circ} \mathrm{C}-25^{\circ} \mathrm{C}\right)$ on reverse $12 \mathrm{~h}$ light-dark cycles. All experimental procedures were approved by the Institutional Animal Care Committee at Memorial University of Newfoundland following the guidelines set by the Canadian Council on Animal Care under the protocol number 14-01-M.

\section{Experimental design}

\section{Cannula surgery}

Two cannulae were anchored in dental acrylic (Lang Dental) such that they were separated laterally by $\sim 4 \mathrm{~mm}$ and extended beyond the acrylic $\sim 0.5-1 \mathrm{~mm}$. When the dental acrylic had hardened, excess acrylic was trimmed off to make the cannulae assembly as small as practical. The cannulae were sonicated to remove excess acrylic particles inside the cannulae. Insect pins (size 00, diameter $0.3 \mathrm{~mm}$, Ento Sphinx) were placed inside the cannulae to prevent blocking.

On PND 5, rat pups were anesthetized by hypothermia and placed in a stereotaxic apparatus. The skull was exposed and two small holes were drilled over the central region of each olfactory bulb. The cannulae were implanted into the olfactory bulb and cemented to the skull. The skin was sutured together and pups were allowed to recover from anesthesia on warm bedding before being returned to the dam.

\section{Drug preparation}

TSA (Cedarlane) was dissolved in 100\% dimethyl sulfoxide (DMSO, EMD Chemicals Inc.) to prepare a stock solution (stock concentration $1 \mu \mathrm{g} / \mu \mathrm{L}$ ) and aliquoted as $10 \mu \mathrm{L}$ in each vial to store at $-20^{\circ} \mathrm{C}$. To make the experimental concentration, $10 \mu \mathrm{L}$ TSA was diluted with $190 \mu \mathrm{L}$ of $10 \%$ DMSO to make $200 \mu \mathrm{L}$ total volume (working concentration $0.05 \mu \mathrm{g} / \mu \mathrm{L}$ ) as described previously (Wang et al. 2013). One microliter of $0.05 \mu \mathrm{g}$ tubacin (Sigma-Aldrich) was prepared in the same manner as TSA and in the same concentration as TSA.

\section{Drug infusion}

Infusion cannulae were made from 30 gauge stainless steel tubing cut to a length of $\sim 7 \mathrm{~mm}$ and inserted into PE-20 polypropylene tubing (inner diameter $0.38 \mathrm{~mm}$, outer diameter $1.09 \mathrm{~mm}$, Becton Dickinson). For bilateral OB infusion, the end of the PE-20 tubing was attached over the needle of a $10 \mu \mathrm{L}$ microsyringe (cemented needle 26s gauge, needle length 2 in., Hamilton Company). On PND 6, 20 min before training, pups received intrabulbar infusion of $1.0 \mu \mathrm{L}$ of $0.05 \mu \mathrm{g}$ TSA or tubacin into each olfactory bulb via the cannula implanted the previous day. Hamilton syringes and a multisyringe pump (Harvard Apparatus) were used to infuse $1 \mu \mathrm{L}$ of TSA or tubacin into each olfactory bulb over a 3-min period.

\section{Odor preference training and testing procedure}

\section{Training}

A single 10-min training session was performed on PND 6 rat pups in temperature controlled $\left(28^{\circ} \mathrm{C}\right)$ behavior rooms. After the drug infusion, pups were placed on peppermint-scented bedding (specifically, in those experiments where preference memory in presence of peppermint were compared with control groups) or orange-scented bedding (one experiment, see Fig. 5) for $10 \mathrm{~min}$ and stroked with a paint brush for $30 \mathrm{sec}$ every other $30 \mathrm{sec}$. Pups in the nonlearning condition were placed on the peppermint-scented bedding for $10 \mathrm{~min}$ without stroking. Peppermint-scented bedding was prepared by adding $0.3 \mathrm{~mL}$ of peppermint extract (GE Barbour Inc.) to $500 \mathrm{~mL}$ of regular unscented woodchip bedding and covered for $10 \mathrm{~min}$. Orange-scented bedding was prepared in a similar way by adding $0.3 \mathrm{~mL}$ of orange oil (natural, cold compressed, California origin, Sigma-Aldrich) to $500 \mathrm{~mL}$ of regular unscented woodchip bedding. Peppermint- or orange-scented bedding was then left uncovered in a fume hood for $10 \mathrm{~min}$ allowing any solvent to evaporate. Pups were returned to the dam immediately after training until sacrifice or further testing.

\section{Testing}

During testing, a two-odor choice test was carried out in a stainless steel test box placed over two training boxes. For the majority of tests, one box contained peppermint-scented bedding, and the other contained normal, unscented bedding. Testing boxes were separated by a $2-\mathrm{cm}$ neutral zone. To begin testing, each rat pup, one at a time, was removed from the dam and transferred to a temporary holding cage with no bedding and kept in the testing room where the dam and other pups are being caged to prevent odor contamination. To start the testing, the pup was placed in the neutral zone of the test box. The amount of time the pup spent on either peppermint-scented bedding or normal bedding was recorded during each of five 1-min trials. The average time spent over peppermint-scented bedding or normal bedding was calculated for each pup. Each pup was given a 30-sec resting time between each of five 1-min trials. During this 30-sec resting time, the pup was returned to the holding cage. In another experiment, pups were tested with orange-scented bedding versus unscented bedding and the percentage of time the pup spent over the orangescented bedding was calculated.

\section{Behavioral procedures of immunohistochemistry}

AMPA (GluA1) receptor expression was examined by immunohistochemistry in the olfactory bulb $5 \mathrm{~d}$ after odor-stroke training. To accomplish this, TSA was infused into one bulb and vehicle was infused into the contralateral bulb. After infusion, pups were exposed to peppermint paired with $10 \mathrm{~min}$ of stroking using a paint brush (see Figs. 3, 4). Pups were perfused $5 \mathrm{~d}$ after training and brains processed for immunohistochemistry as described below.

\section{Perfusion and IHC procedures}

At $5 \mathrm{~d}$ (GluA1) after training, animals were anesthetized by sodium pentobarbital (80 mg/kg, Bimeda-MTC Animal Health Inc.) and perfused transcardially with ice-cold $0.9 \%$ saline solution ( 1 $\mathrm{min}$ ) followed by ice-cold fixative: $4 \%$ paraformaldehyde (Fisher Scientific) in $0.1 \mathrm{M}$ phosphate buffer, $\mathrm{pH}$ 7.4. Brains were removed from the skull and post-fixed for $1 \mathrm{~h}$ in the same fixative solution, after which they were immersed in $20 \%$ sucrose solution overnight at $4^{\circ} \mathrm{C}$.

The next day, brains were flash-frozen and $30 \mu \mathrm{m}$ coronal sections of the entire bulb were cut in a cryostat (Thermo Scientific) at $-15^{\circ} \mathrm{C}$. Sections were directly mounted onto slides. The primary antibodies rabbit GluA1 (1/10,000, Abcam) was diluted in phosphate-buffered saline (PBS) with $0.2 \%$ Triton X-100, $0.002 \%$ sodium azide, and $2 \%$ normal goat serum and applied to sections overnight at $4^{\circ} \mathrm{C}$. The next day, sections were washed in PBS for $3 \times 5$ min and incubated in a biotinylated anti-rabbit secondary antibody (Vectastain Elite, Vector Laboratories Inc.) dissolved in PBS with $0.2 \%$ Triton X-100 for $1 \mathrm{~h}$. Then sections were washed in PBS for $3 \times 5 \mathrm{~min}$ and avidin/biotinylated enzyme $(\mathrm{A}+\mathrm{B})$ solution (Vectastain Elite, Vector Laboratories Inc.) was added followed by incubation for $1 \mathrm{~h}$. Next, sections were incubated in $0.05 \%$ diaminobenzidine (DAB) with $0.01 \%$ hydrogen peroxide 
$\left(\mathrm{H}_{2} \mathrm{O}_{2}\right)$ for $3 \mathrm{~min}$ and washed in PBS for $3 \times 5 \mathrm{~min}$. Then slides were rinsed with distilled water for $10 \mathrm{sec}$. Afterward, sections were dehydrated and cover-slipped with Permount (Fisher Scientific). Olfactory bulb sections (vehicle-treated side and TSA-treated side) from each pup were processed on the same slide at identical times for incubation in the antibodies and development in DAB solution. Thus, this drug infusion and processing methods provided intra-animal control for IHC.

\section{Image analysis for GluAl IHC}

Images of sections were captured with a CCD camera (Leica Microsystems Ltd.) connected to the Leitz microscope (Leitz) at $4 \times$ magnification. Leica Application Suite software (Leica Microsystems Ltd., version 4.2.0) was used to process and store the images. The light intensity of the microscope was kept at the same level for all the sections from all animals analyzed. The intensity of GluA1 staining was analyzed using Image J analysis software (National Institutes of Health, version 1.46p). Regions analyzed included the dorsolateral and dorsomedial quadrants of the GL known to be responsive to peppermint (Johnson and Leon 2007) and the dorsolateral and dorsomedial quadrants of EPL for each section in the olfactory bulb. To analyze the sections, the optical density (OD) of the olfactory nerve layer was used as a background OD for the section. This was accomplished by drawing four $\sim 100$ - $\mu \mathrm{m}$ diameter ovals on the olfactory nerve in each section and averaging the OD reading. To measure the OD of the glomeruli, eight glomeruli were marked in each quadrant and the OD averaged for that quadrant in each section. The external plexiform layer was analyzed similarly by drawing eight ( $100 \mu \mathrm{m}$ diameter $)$ ovals in each quadrant and averaging the OD. Measurements of OD were taken from four rostral-to-caudal levels of the glomeruli and external plexiform layers from each pup. The relative OD of the region of interest (ROI) was obtained by using the following formula: (OD of background - OD of ROI)/OD of background.

\section{Experimental groups for immunoblotting}

Rat pups were divided into three groups: $\mathrm{Sal}+\mathrm{O} / \mathrm{O}$, Sal $+\mathrm{O} / \mathrm{S}$, and $\mathrm{TSA}+\mathrm{O} / \mathrm{S}$. Each group was further subdivided into three time points $(24 \mathrm{~h}, 48 \mathrm{~h}$, and $5 \mathrm{~d}$ ) after training.

Samples were collected at three different time points after conditioning. After decapitation, olfactory bulbs were quickly removed and frozen on dry ice. Tissue was stored in lysis tubes (Micro tube $0.5 \mathrm{~mL}$, SARSTEDT AG \& Co.) containing beads (1.4 mm Zirconium oxide beads, Precellys 24$)$ at $-80^{\circ} \mathrm{C}$ until processing.

\section{Crude membrane fraction extraction protocol}

Tissues were homogenized in $100 \mu \mathrm{L}$ sucrose buffer at $5500 \mathrm{rpm}$ for $20 \mathrm{sec}$ in a homogenizer (Precellys 24). The homogenate was centrifuged at $1000 \mathrm{~g}$ at $4^{\circ} \mathrm{C}$ for $15 \mathrm{~min}$ to remove nuclei and incompletely homogenized material (P1). The supernatant (S1) was collected and centrifuged at $10,000 \mathrm{~g}$ at $4^{\circ} \mathrm{C}$ for $20 \mathrm{~min}$ to obtain the membrane fraction (P2) and removed the cytosolic fraction (S2). The pellet (P2) was resuspended in $80 \mu \mathrm{L} 1 \times$ STE (sodium dodecyl sulfate [SDS] tris-ethylenediaminetetraacetic acid [EDTA]) buffer. P2 samples were sonicated and then heated to $90^{\circ} \mathrm{C}$ for $3 \mathrm{~min}$ to solubilize the pellet. Although many types of membrane components are found in these extracts, we previously observed by electron microscopy that many of the components are synaptoneurosomes (Cui et al. 2011).

\section{Protein concentration determination}

Protein concentrations for each sample were determined using the BCA Protein Assay adapted for a 96-well plate (Pierce BCA Protein Assay kit, Thermo Scientific) using bovine serum albumin to generate a standard curve. Samples were read at $562 \mathrm{~nm}$ (PolarStar Optima; BMG Technologies Inc.) and the optical density used to calculate the volume required to load $50 \mu \mathrm{g}$ of protein per sample into the wells of polyacrylamide gels used for electrophoresis.

\section{Immunoblotting}

Samples were $50 \mu \mathrm{g}$ of protein lysate mixed with $5 \times$ sample buffer (50 mM Tris-HCl, pH 6.8, 10\% glycerol, 5\% 2-mercaptoethanol, $2 \%$ SDS, $0.125 \%$ bromophenol blue) and water (to adjust total volume to $25 \mu \mathrm{L}$ ). Samples were mixed and heated for $5 \mathrm{~min}$ at $100^{\circ} \mathrm{C}$ prior to loading onto a $10 \%$ polyacrylamide gel. Samples were then transferred to nitrocellulose membrane (Millipore) at $100 \mathrm{~V}$ for $60 \mathrm{~min}$ at $4^{\circ} \mathrm{C}$. Following transfer, nitrocellulose membranes were washed in Tris-buffered saline with $0.1 \%$ Tween (TBST) for $3 \times 5 \mathrm{~min}$. Blots were blocked in 5\% nonfat dry milk + TBST for $1 \mathrm{~h}$ at room temperature. After washing, blots were incubated in primary antibody (rabbit polyclonal GluA1; Abcam, in blocking buffer) overnight at $4^{\circ} \mathrm{C}$ with continuous shaking. Blots were then washed in TBST $(3 \times 10 \mathrm{~min})$ and incubated in secondary antibody (goat anti-rabbit conjugated with horseradish peroxidase; Thermo Scientific) with 5\% nonfat dry milk + TBST, for $1.5 \mathrm{~h}$ at room temperature and then washed in TBST $(3 \times 10 \mathrm{~min})$.

Specific protein bands were visualized using chemiluminescence (Supersignal West Pico; Thermo Scientific). Blots were exposed for varying lengths of time to film (Kodak Clinic Select Green; Eastman Kodak company).

For determining AMPA receptor (GluA1) expression, immunoblots were reprobed with $\beta$-Actin (purified rabbit anti- $\beta$-actin, 1/5000, Cell Signaling) as a loading control.

\section{Statistical analysis}

For analyzing behavioral experiments, one-way ANOVA with a Tukey's post hoc test was used to make comparisons among different groups. For immunoblotting experiments, GluA1 expression was analyzed by two-way ANOVA followed by Tukey's post hoc comparisons with both time and groups as factors. For image analysis of GluA1 IHC, paired $t$-tests were used to compare between the saline-treated $\mathrm{OB}$ versus TSA-treated OB obtained from the same animal. An unpaired two-tailed $t$-test was performed to evaluate the memory specificity for the paired odor between two groups. Differences between groups were considered significant when $P$ values were $<0.05$.

\section{Acknowledgments}

This work was funded by Canadian Institutes of Health Research grant MOP-53761 to J.H.M. and C.W.H. and Natural Sciences and Engineering Research Council of Canada discovery grant 418451-2013 to Q.Y. Thanks to Dr. Charles Malsbury for comments on drafts of this manuscript.

\section{References}

Bozza TC, Kauer JS. 1998. Odorant response properties of convergent olfactory receptor neurons. J. Neurosci 18: 4560-4569.

Chen S, Owens GC, Makarenkova H, Edelman DB. 2010. HDAC6 regulates mitochondrial transport in hippocampal neurons. PLOS ONE 5: e10848.

Cuadrado-Tejedor M, Garcia-Barroso C, Sánchez-Arias JA, Rabal O, Pérez-González M, Mederos S, Ugarte A, Franco R, Segura V, Perea G, et al. 2017. A first-in-class small-molecule that acts as a dual inhibitor of HDAC and PDE5 and that rescues hippocampal synaptic impairment in Alzheimer's disease mice. Neuropsychopharmacology 42: 524-539.

Cui W, Darby-King A, Grimes MT, Howland JG, Wang YT, McLean JH, Harley CW. 2011. Odor preference learning and memory modify GluA1 phosphorylation and GluA1 distribution in the neonate rat olfactory bulb: testing the AMPA receptor hypothesis in an appetitive learning model. Learn Mem 18: 283-291.

Diaz-Maroto MC, Castillo N, Castro-Vazquez L, de Torres C, Perez-Coello M. 2008. Authenticity evaluation of different mints based on their volatile composition and olfactory profile. J Essent Oil Bear Plants 11: 1-16.

Fischer A, Sananbenesi F, Wang X, Dobbin M, Tsai L-H. 2007. Recovery of learning and memory is associated with chromatin remodelling. Nature 447: $178-182$.

Fontaine CJ, Harley CW, Yuan Q. 2013. Lateralized odor preference training in rat pups reveals an enhanced network response in anterior piriform cortex to olfactory input that parallels extended memory. J Neurosci 33: $15126-15131$.

Grimes MT, Harley CW, Darby-King A, McLean JH. 2012. PKA increases in the olfactory bulb act as unconditioned stimuli and provide evidence for 
parallel memory systems: pairing odor with increased PKA creates intermediate- and long-term, but not short-term, memories. Learn Mem 19: $107-115$.

Grimes MT, Powell M, Gutierrez SM, Darby-King A, Harley CW, McLean JH. 2015. Epac activation initiates associative odor preference memories in the rat pup. Learn Mem 22: 74-82.

Guan Z, Giustetto M, Lomvardas S, Kim JH, Miniaci MC, Schwartz JH, Thanos D, Kandel ER. 2002. Integration of long-term-memory-related synaptic plasticity involves bidirectional regulation of gene expression and chromatin structure. Cell 111: 483-493.

Haettig J, Stefanko DP, Multani ML, Figueroa DX, McQuown SC, Wood MA. 2011. HDAC inhibition modulates hippocampus-dependent long-term memory for object location in a CBP-dependent manner. Learn Mem 18: 71-79.

Johnson BA, Leon M. 2007. Chemotopic odorant coding in a mammalian olfactory system. J Comp Neurol 503: 1-34.

Kikuta S, Fletcher ML, Homma R, Yamasoba T, Nagayama S. 2013. Odorant response properties of individual neurons in an olfactory glomerular module. Neuron 77: 1122-1135.

Korzus E, Rosenfeld MG, Mayford M. 2004. CBP histone acetyltransferase activity is a critical component of memory consolidation. Neuron 42: 961-972.

Levenson JM, Sweatt JD. 2005. Epigenetic mechanisms in memory formation. Nat Rev Neurosci 6: 108-118.

Levenson JM, O'Riordan KJ, Brown KD, Trinh MA, Molfese DL, Sweatt JD. 2004. Regulation of histone acetylation during memory formation in the hippocampus. J Biol Chem 279: 40545-40559.

Lu WY, Man HY, Ju W, Trimble WS, MacDonald JF, Wang YT. 2001. Activation of synaptic NMDA receptors induces membrane insertion of new AMPA receptors and LTP in cultured hippocampal neurons. Neuron 29: 243-254.

Lynch G, Baudry M. 1984. The biochemistry of memory: a new and specific hypothesis. Science 224: 1057-1063.

Malinow R, Malenka RC. 2002. AMPA receptor trafficking and synaptic plasticity. Annu Rev Neurosci 25: 103-126.

McLean JH, Darby-King A, Harley CW. 2005. Potentiation and prolongation of long-term odor memory in neonate rats using a phosphodiesterase inhibitor. Neuroscience 135: 329-334.

Mobley RJ, Raghu D, Duke LD, Abell-Hart K, Zawistowski JS, Lutz K, Gomez SM, Roy S, Homayouni R, Johnson GL, Abell AN. 2017. MAP3K4 controls the chromatin modifier HDAC6 during trophoblast stem cell epithelial-to-mesenchymal transition. Cell Rep 18: 2387-2400.

Okutani F, Yagi F, Kaba H. 1999. GABAergic control of olfactory learning in young rats. Neuroscience 93: 1297-1300.

Perry S, Kiragasi B, Dickman D, Ray A. 2017. The role of histone deacetylase 6 in synaptic plasticity and memory. Cell Rep 18: 1337-1345.

Selcher JC, Xu W, Hanson JE, Malenka RC, Madison DV. 2012. Glutamate receptor subunit GluA1 is necessary for long-term potentiation and synapse unsilencing, but not long-term depression in mouse hippocampus. Brain Res 1435: 8-14.

Siow D, Wattenberg B. 2014. The histone deacetylase-6 inhibitor tubacin directly inhibits de novo sphingolipid biosynthesis as an off-target effect. Biochem Biophys Res Commun 449: 268-271.

Sullivan RM, Hofer MA, Brake SC. 1986. Olfactory-guided orientation in neonatal rats is enhanced by a conditioned change in behavioral state. Dev Psychobiol 19: 615-623.

Sullivan RM, Leon M. 1986. Early olfactory learning induces an enhanced olfactory bulb response in young rats. Brain Res 392: 278-282.

Vecsey CG, Hawk JD, Lattal KM, Stein JM, Fabian SA, Attner MA, Cabrera SM, McDonough CB, Brindle PK, Abel T, et al. 2007. Histone deacetylase inhibitors enhance memory and synaptic plasticity via CREB:CBP-dependent transcriptional activation. J Neurosci 27: 6128-6140.

Wang YJ, Okutani F, Murata Y, Taniguchi M, Namba T, Kaba H. 2013. Histone acetylation in the olfactory bulb of young rats facilitates aversive olfactory learning and synaptic plasticity. Neuroscience 232: 21-31.

Yeh S-H, Mao S-C, Lin H-C, Gean P-W. 2006. Synaptic expression of glutamate receptor after encoding of fear memory in the rat amygdala. Mol Pharmacol 69: 299-308.

Yuan Q, Harley CW, McLean JH, Knöpfel T. 2002. Optical imaging of odor preference memory in the rat olfactory bulb. J Neurophysiol 87: 3156-3159.

Zovkic IB, Guzman-Karlsson MC, Sweatt JD. 2013. Epigenetic regulation of memory formation and maintenance. Learn Mem 20: 61-74.

Received April 20, 2017; accepted in revised form June 7, 2017. 


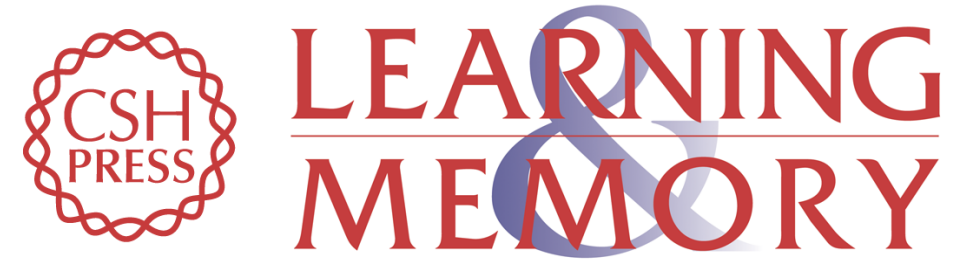

\section{Histone deacetylase inhibition induces odor preference memory extension and maintains enhanced AMPA receptor expression in the rat pup model}

Sriya Bhattacharya, Bandhan Mukherjee, Jules J.E. Doré, et al.

Learn. Mem. 2017, 24:

Access the most recent version at doi:10.1101/Im.045799.117

References This article cites 32 articles, 11 of which can be accessed free at: http://learnmem.cshlp.org/content/24/10/543.full.html\#ref-list-1

Creative This article is distributed exclusively by Cold Spring Harbor Laboratory Press for the Commons first 12 months after the full-issue publication date (see

License http://learnmem.cshlp.org/site/misc/terms.xhtml). After 12 months, it is available under a Creative Commons License (Attribution-NonCommercial 4.0 International), as described at http://creativecommons.org/licenses/by-nc/4.0/.

Email Alerting Receive free email alerts when new articles cite this article - sign up in the box at the Service top right corner of the article or click here. 